\title{
Microbial community functional structure in response to micro-aerobic conditions in sulfate-reducing sulfur-producing bioreactor
}

\author{
Hao $\mathrm{Yu}^{1,2}$, Chuan Chen ${ }^{1, *}$, Jincai $\mathrm{Ma}^{3}$, Xijun $\mathrm{Xu}^{1}$, Ronggui $\mathrm{Fan}^{2}$, Aijie Wang ${ }^{1,4, *}$ \\ 1. State Key Laboratory of Urban Water Resource and Environment, Harbin Institute of Technology, Harbin 150090, China. \\ E-mail: micro_yh@126.com \\ 2. School of Environmental Science and Engineering, Liaoning Technical University, Fuxin 123000, China \\ 3. Biosciences and Biotechnology Division, Lawrence Livermore National Laboratory, Livermore, California 94550, USA \\ 4. Research Center for Eco-Environmental Sciences, Chinese Academy of Sciences, Beijing 100085, China
}

\section{A R T I C L E I N F O}

\section{Article history:}

Received 22 September 2013

revised 30 October 2013

accepted 07 November 2013

\section{Keywords:}

micro-aerobic condition

elemental sulfur recovery

microbial community

functional gene array

DOI: $10.1016 /$ S1001-0742(13)60589-6

\begin{abstract}
A B S T R A C T
Limited oxygen supply to anaerobic wastewater treatment systems had been demonstrated as an effective strategy to improve elemental sulfur $\left(\mathrm{S}^{0}\right)$ recovery, coupling sulfate reduction and sulfide oxidation. However, little is known about the impact of dissolved oxygen (DO) on the microbial functional structures in these systems. We used a high throughput tool (GeoChip) to evaluate the microbial community structures in a biological desulfurization reactor under micro-aerobic conditions (DO: $0.02-0.33 \mathrm{mg} / \mathrm{L}$ ). The results indicated that the microbial community functional compositions and structures were dramatically altered with elevated DO levels. The abundances of $d s r A / B$ genes involved in sulfate reduction processes significantly decreased ( $p<0.05$, LSD test) at relatively high DO concentration (DO: $0.33 \mathrm{mg} / \mathrm{L}$ ). The abundances of sox and $f c c A / B$ genes involved in sulfur/sulfide oxidation processes significantly increased ( $p<0.05$, LSD test) in low DO concentration conditions (DO: $0.09 \mathrm{mg} / \mathrm{L}$ ) and then gradually decreased with continuously elevated DO levels. Their abundances coincided with the change of sulfate removal efficiencies and elemental sulfur $\left(\mathrm{S}^{0}\right)$ conversion efficiencies in the bioreactor. In addition, the abundance of carbon degradation genes increased with the raising of DO levels, showing that the heterotrophic microorganisms (e.g., fermentative microorganisms) were thriving under micro-aerobic condition. This study provides new insights into the impacts of micro-aerobic conditions on the microbial functional structure of sulfatereducing sulfur-producing bioreactors, and revealed the potential linkage between functional microbial communities and reactor performance.
\end{abstract}

\section{Introduction}

As a common contaminant, sulfate is found in the effluents of many industries, such as food processing, chemical industry, paper manufacturing and petroleum refining. One of the prevailing problems associated with the anaerobic treatment of sulfate-laden wastewater is the large amounts

\footnotetext{
${ }^{*}$ Corresponding author. E-mail: echo110244@126.com (Chuan Chen); waj0578@hit.edu.cn (Aijie Wang)
}

of sulfide generation by sulfate-reducing bacteria (SRB). It is well known that sulfide may result in severe corrosive and toxic effects on sewers, ecosystems and living species (Xu et al., 2012). Biological sulfide removal is a promising strategy to solve this problem since it is environmentally friendly and cost-effective (Chen et al., 2008). Sulfide can be removed coupled to sulfate reduction by sulfide-oxidizing bacteria (SOB), typically colorless sulfur bacteria, which oxidize reduced sulfur compounds using oxygen as the electron acceptor and $\mathrm{CO}_{2}$ as the carbon source (Sahinkaya et al., 2011). Moreover, sev- 
eral colorless sulfur bacteria including Thiobacillus sp., Thiomicrospira sp. and Thioalkalivibrio sp. have been proved to be responsible for sulfide oxidation in the biodesulfurization process (Huang et al., 1996; McComas et al., 2001; Sorokin et al., 2008).

Recently, there has been increased interest in production of elemental sulfur $\left(\mathrm{S}^{0}\right)$ in bio-desulfurization processes, because $\mathrm{S}^{0}$ can be reused as fertilizer after separation from the effluent or biosolids (Celis-García et al., 2008). It has been demonstrated that the sulfide oxidation process is regulated by the oxygen availability, and $\mathrm{S}^{0}$ is the major final product (Janssen et al., 1995; Kobayashi et al., 2011). Biological sulfide control by introduction of limited amounts of oxygen/air into anaerobic systems has been extensively investigated in various reactors (Lohwacharin and Annachhatre, 2010; Sahinkaya et al., 2011; van der Zee et al., 2007), showing a high conversion efficiency of sulfide to $S^{0}$. A conceptual process which integrates SRB and SOB in a single expanded granular sludge bed (EGSB) reactor has been operated under different micro-aerobic conditions (Xu et al., 2012). Their results demonstrated that recovery of $\mathrm{S}^{0}$ was effectively controlled by the amount of oxygen in the bioreactors.

Although the $\mathrm{S}^{0}$ conversion efficiency and sulfide removal efficiency under micro-aerobic conditions had been widely investigated for optimized bioreactor operations, very little is known about the change of diversity, structure of microbial communities, and functional species (e.g. $\mathrm{SRB}$ and $\mathrm{SOB}$ ) in response to introduction of oxygen into anaerobic reactors. In addition, research on the metabolic potential of microbial communities at the gene level is important to assess and improve the overall performance of bioreactors. To date, the information on microbial functional structures in bio-desulfurization systems is limited, which may be due to the complexity of functional species and drawbacks of conventional molecular approaches for microbial ecology detection (Bai et al., 2013; Liu et al., 2010; Zhou et al., 2010). Recently, GeoChip-based metagenomics technology has been proved to be a powerful and high throughput tool for characterizing functional microbial communities in both natural and artificial (biore- actor) environments (Bai et al., 2013; He et al., 2010; Liu et al., 2010). The aim of this work is to investigate the change of the diversity, structure, and abundances of functional genes/species at different dissolved oxygen (DO) levels using a functional gene array (GeoChip) and to reveal the linkage between the abundances of functional gene/species and the performance of the reactor, such as sulfate removal efficiency and $S^{0}$ conversion efficiency.

\section{Materials and methods}

\subsection{Reactor setup and working conditions}

The continuous experiment was conducted in a 4-L Plexiglas EGSB reactor, which has an internal diameter of 50 $\mathrm{mm}$ and a height of $120 \mathrm{~cm}$. The structure and detailed information of the reactor was reported previously $(\mathrm{Xu}$ et al., 2012). The bioreactor was operated at a thermal state of $(30 \pm 1)^{\circ} \mathrm{C}$ with hydraulic retention time (HRT) of $18 \mathrm{hr}$. The entire experiment consisted of six stages as listed in Table 1. As a single controllable parameter, the concentration range of DO was varied from 0.02 to 0.33 $\mathrm{mg} / \mathrm{L}$ by adjusting the aeration flow rates.

The bioreactor was initially inoculated with granules from an EGSB reactor described previously (Chen et al., 2008). The sulfate-laden synthetic wastewater containing $1000 \mathrm{mg} / \mathrm{L}$ of $\mathrm{SO}_{4}^{2-}, 3000 \mathrm{mg} \mathrm{COD} / \mathrm{L}$ of lactate, $220 \mathrm{mg} / \mathrm{L}$ of $\mathrm{K}_{2} \mathrm{HPO}_{4}, 100 \mathrm{mg} / \mathrm{L}$ of $\mathrm{CaCl}_{2}$ and $100 \mathrm{mg} / \mathrm{L}$ of $\mathrm{MgCl}_{2}$ was fed into the bioreactor. The $\mathrm{pH}$ was maintained at 8.0 \pm 0.3 by using sodium bicarbonate $\left(\mathrm{NaHCO}_{3}\right)$ solution.

\subsection{DNA preparation and hybridization}

Twelve sludge samples were collected from stage I (DO: $0.02 \mathrm{mg} / \mathrm{L}$ ), II (DO: $0.09 \mathrm{mg} / \mathrm{L}$ ), III (DO: $0.11 \mathrm{mg} / \mathrm{L}$ ) and VI (DO: $0.33 \mathrm{mg} / \mathrm{L})$. In each stage, samples were continuously collected from the last three operational days as replicates for community analysis and listed as follows: stage I (S1a, S1b, S1c), stage II (S2a, S2b, S2c), stage III (S3a, S3b, S3c) and stage VI (S6a, S6b, S6c). Total

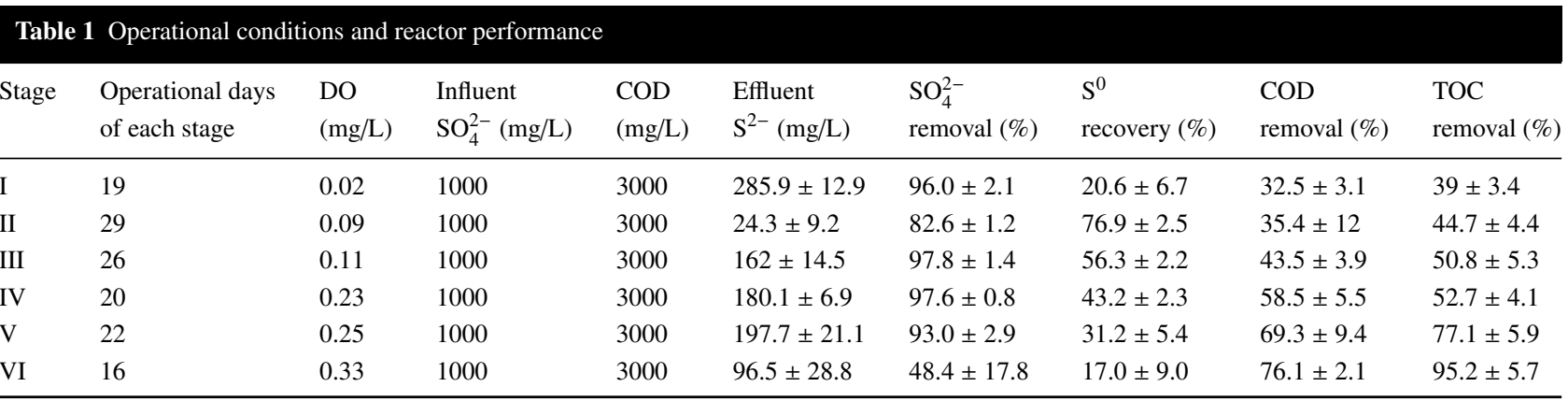

Performance data are presented as mean \pm standard deviation. The performance at the last five time points in each stage was selected to calculate statistical data. 
DNA was extracted from $300 \mu \mathrm{L}$ of the granule suspension by freeze-grinding methods (Zhou et al., 1996). The DNA was quantified using a NanoDrop spectrophotometer (ND1000, Nanodrop Inc., USA) and PicoGreen (Invitrogen, USA). Approximately $1.5 \mu \mathrm{g}$ DNA was labeled with fluorescent dye Cy3 (GE Healthcare, USA) using a random priming method as previously described (Wu et al., 2006). Labeled DNA was purified with a QIA Quick Purification kit (Qiagen, USA) and then dried in a SpeedVac (ThermoSavant, USA) for $50 \mathrm{~min}$ at $45^{\circ} \mathrm{C}$.

As a new version of functional gene array, GeoChip 4.2 was employed to characterize the functional structure of granule microbial communities. GeoChip 4.2 contains 93,902 50-mer oligonucleotide probes targeting more than 156,719 genes from 738 functional families. Hybridizations were carried out for $16 \mathrm{hr}$ at $42^{\circ} \mathrm{C}$ on a MAUI hybridization station (BioMicro, USA). After hybridization, GeoChips were scanned by NimbleGen MS200 (Madison, USA) at a laser power of $100 \%$.

\subsection{Analytical methods}

The concentrations of sulfate and thiosulfate were analyzed by ion chromatography (Dionex ICS-3000, USA). Before measurement, the liquor samples were centrifuged, filtered $(0.45-\mathrm{mm})$, separated and eluted with an IonPac AG4A AS4A-SC 4-mm analytical column (Chen et al., 2008). Dissolved sulfide concentration was measured with the Methylene Blue method (Trüper and Schlegel, 1964). The concentration of DO was determined with a DO meter (pH/Oxi 340i, WTW, Germany). The $\mathrm{pH}$ and oxidationreduction potential (ORP) was measured by a $\mathrm{pH} / \mathrm{ORP}$ meter (pHS-25, ShangHai, China). The compositions of gas were determined by a gas chromatography system (6890, Agilent, USA). The direct quantitative measurement of $\mathrm{S}^{0}$ production was not available due to a sizable portion of $S^{0}$ remaining in the granule suspension inside the reactor. The concentration of $S^{0}$ could be calculated by a theoretical equation as previously reported (Eq. (1)) (de Graaff et al., 2012):

$$
\left[\mathrm{S}^{0}\right]=[\text { Influent } \mathrm{S}]-\left[\mathrm{SO}_{4}^{2-}\right]-2 \times\left[\mathrm{S}_{2} \mathrm{O}_{3}^{2-}\right]-\left[\mathrm{HS}^{-}\right]
$$

\subsection{Data analysis}

Pre-processed data were obtained at the website (http://ieg.ou.edu/microarray/) for further analysis. The microbial diversity indices and detrended correspondence analysis (DCA) were calculated using R 2.9.1 (http://www.r-project.org/). The statistical differences of functional genes between different DO concentration stages were analyzed by analysis of variance (ANOVA), least significant difference (LSD) test and the two-tailed $t$-test. Hierarchical cluster analysis was performed using CLUSTER 3.0 software (http://rana.stanford.edu), and trees were visualized using TREEVIEW (http://rana.stanford.edu/).

\section{Results}

\subsection{EGSB reactor performance}

Table 1 presents a summary of operational parameters and overall performance of the reactor at different stages. The sulfate removal efficiency remained high (82.6\%-97.8\%) in stage I-V (DO: $0.02-0.25 \mathrm{mg} / \mathrm{L}$ ), and decreased sharply to $48.4 \%$ in stage VI (DO: $0.33 \mathrm{mg} / \mathrm{L}$ ). The $\mathrm{S}^{0}$ conversion efficiency was at a low level $(20.6 \%)$ in stage I $(D O=0.02$ $\mathrm{mg} / \mathrm{L}$ ), and then strikingly increased to $76.9 \%$ in stage II (DO: $0.09 \mathrm{mg} / \mathrm{L}$ ), whereafter it decreased progressively from $56.3 \%$ to $17.0 \%$ when the DO concentration was increased from 0.11 to $0.33 \mathrm{mg} / \mathrm{L}$ in stage III-VI. During the entire experimental period, the COD and TOC removal efficiencies increased with time. In stage VI, the COD and TOC removal efficiencies reached $76.1 \%$ and $95.2 \%$, respectively. Overall, the results showed that the performance of the bioreactor was significantly affected by elevated DO levels.

\subsection{Overall microbial community changes in response to increased DO concentration}

Based on the functional genes detected by GeoChip 4.2, the results of DCA and permutational multivariate analysis of variance (adonis) showed significant variations $(F=$ 5.5973, $P<0.001)$ between microbial communities in the bioreactor when supplied with different levels of DO (Fig. 1). S1 samples were well separated from S2, S3 and S6 samples by DCA1, while $\mathrm{S} 2$ and $\mathrm{S} 3$ samples were well separated by DCA2. Additionally, a significant effect of DO on overall microbial communities was also observed in the richness of the detected functional gene numbers $(p<$ 0.01, ANOVA) and microbial diversity indices (Shannon-

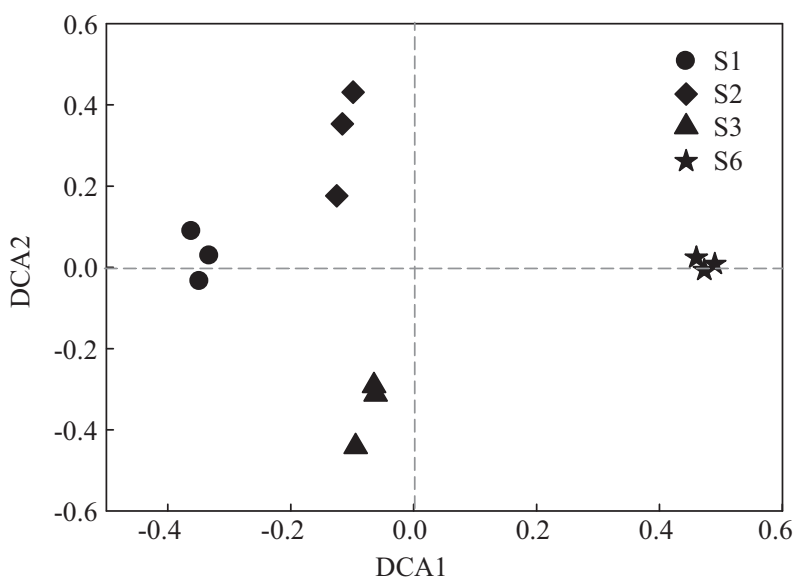

Fig. 1 Detrended correspondence analysis (DCA) of microbial communities in different stages based on functional genes detected. S1, S2, S3, S6 represent the samples collected from stages $\mathrm{S} 1$ (DO: $0.02 \mathrm{mg} / \mathrm{L}$ ), S2 (DO: $0.09 \mathrm{mg} / \mathrm{L}), \mathrm{S} 3$ (DO: $0.11 \mathrm{mg} / \mathrm{L}$ ) and S6 (DO: $0.33 \mathrm{mg} / \mathrm{L}$ ), respectively. 
Weaver $\left(H^{\prime}\right)$ and Simpson reciprocal $(1 / D)$ indexes) $(p<$ 0.01, ANOVA). As presented in Fig. 2, the richness and diversity indices increased with elevated DO levels. Significantly higher Simpson's indices $(1 / D)$, Shannon-Weaver indices $\left(H^{\prime}\right)$ and functional gene numbers $(p<0.05)$ were obtained in S6 and S3 than in S1, while the differences were not significant between S2 and any of the other stage samples based on the LSD test. These results indicated that the diversity, structure and composition of bioreactor microbial communities were greatly altered under different DO level conditions.

\subsection{Effect of DO on functional gene category involved in carbon cycling}

Functional genes involved in carbon degradation and fixation processes were examined for a better understanding of the diversity and metabolic potential of microbial communities. A total of 2467 carbon degradation genes and 545 carbon fixation genes were detected in 4 stages' samples. Similar to the patterns of richness and diversity indices, the abundances of carbon degradation genes were

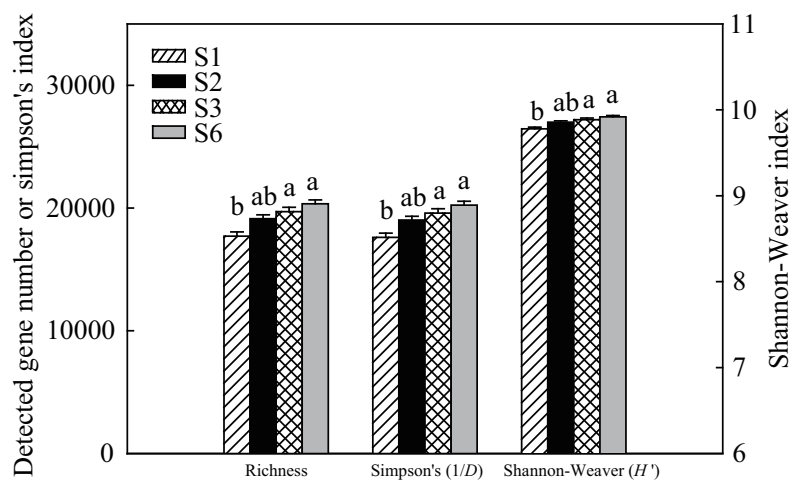

Fig. 2 Detected gene numbers and diversity indices of different stage samples. All data are presented with mean \pm SE. Letters represent significant differences among stages of three parameters at $p<0.05$ by least significant difference (LSD) test.

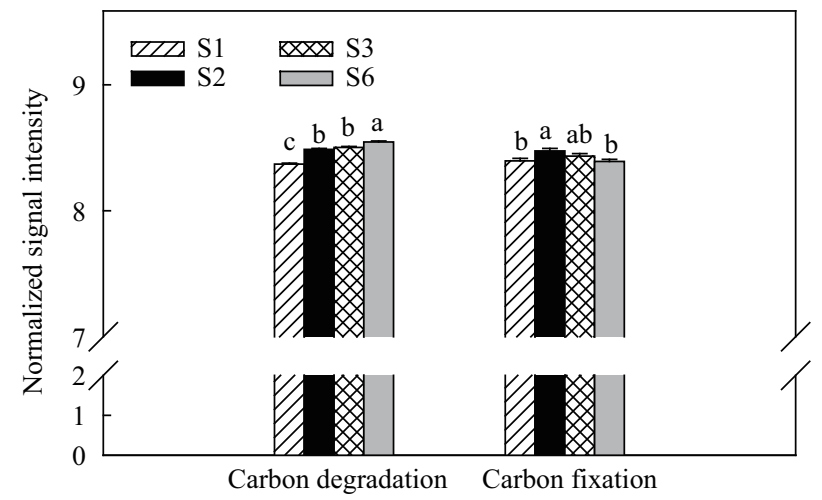

Fig. 3 Normalized signal intensity of functional gene categories involved in carbon cycling process. The signal intensity for each gene category was the average total abundances among 3 replicates. All data are presented with mean \pm SE. Different letters represent significant differences among stages at $p<0.05$ by LSD test. increased with the elevated DO levels (Figs. 2 and 3). The abundances of carbon degradation genes were significantly higher $(p<0.05)$ in S6 than in S1, S2 and S3 $(p<0.05)$. This significant difference was also observed between $\mathrm{S} 2 / \mathrm{S} 3$ and S1 $(p<0.05)$. These results indicated that a faster biological oxygen-dependent utilization of organic carbon source occurred in the bioreactor.

Previous studies revealed that autotrophic bacteria play a key role in sulfide oxidation processes (Friedrich et al., 2005; Jost et al., 2010; Luo et al., 2011; Sahinkaya et al., 2011). Four key enzymes for autotrophic carbon fixation pathways (ATP citrate lyase (AclB) for the reductive acetyl-CoA pathway, carbon monoxide dehydrogenase (CODH) for the reductive acetyl-CoA pathway, propionylCoA carboxylase (Pcc) for the 3-hydroxypropionate cycle and ribulose-1, 5-bisphosphate carboxylase/oxygenase (Rubisco) for the Calvin cycle) were analyzed to indicate autotrophic microorganisms. The overall abundances of carbon fixation genes were significantly higher in S2 than in S1 and S6 $(p<0.05)$ (Fig. 3), suggesting that autotrophic microorganisms thrived in stage II. In contrast to Rubisco genes, the overall abundances of $a c l B, C O D H$ and $p c c$ genes were relatively lower, and there was no significant difference observed in the abundances of these genes between different stage samples (Fig. S1 in supplementary data). This indicated that the Calvin cycle may potentially be the major pathway for carbon fixation in the EGSB reactor.

\subsection{Effect of DO on the key genes and species involved in sulfur metabolic process}

To obtain more mechanistic insights into the effect of increased DO concentrations on functional genes and species, several key genes involved in sulfur cycling were analyzed. The $d s r$ gene, encoding dissimilatory sulfite reductase, was served as an indicator of SRB. A total of $334 d s r A$ (26.4\% of overall designed $d s r A$ probes) and $217 d s r B$ genes (24.9\% of overall designed $d s r B$ probes) were detected across all samples. Among these genes, 425 genes $(77.1 \%)$ were from uncultured microorganisms, and 126 genes $(22.9 \%)$ from cultured sulfate-reducing bacteria belonging to 52 genera. As expected, functional species from Desulfovibrio, Desulfotomaculum, Desulfomicrobium, Desulfohalobium, Desulfobulbus were more abundant in the bioreactor. Substantially lower $d s r A / B$ gene numbers (346) were detected in S6 than in S1 (441), S2 (453) and S3 (464). Specifically, seventy $d s r A / B$ genes were present in S1, S2, and S3 but absent in S6. Most of these genes were from uncultured microorganisms (59/70), and 11 were from cultured SRB (3 from Desulfotomaculum ruminis, 2 from Desulfotomaculum geothermicum, 2 from Desulfovibrio vulgaris Hildenborough, 1 from Desulfotomaculum nigrificans, 1 from Desulfohalobium retbaense, 1 from Desulfovibrio fructosovorans and 1 from Desulfovibrio magneticus) (data not shown). Additionally, 
the overall abundances of $d s r A$ and $d s r B$ genes were significantly lower $(p<0.05)$ in S6 than in other 3 stage samples, while the differences were not significant between S1, S2 and S3 (Fig. 4). The results indicated that the SRB were strongly inhibited at DO $=0.33 \mathrm{mg} / \mathrm{L}$. Similar patterns were also observed in the abundance of AprA and AprB genes (encoding dissimilatory adenosine5 '-phosphosulfate reductase).

The sulfur-oxidizing enzyme system (sox) confers several proteins that oxidize reduced sulfur compounds (hydrogen sulfide, sulfur, thiosulfate or sulfite) and transfer the gained electrons to the respiratory chain (Dambe et al., 2005; Friedrich et al., 2000; Rother et al., 2001). A total of 177 sox genes were detected across all samples, which came from 100 different species belonging to 60 genera, especially including several typical sulfide/sulfur-oxidizing genera (e.g. Chlorobium, Paracoccus, Thiobacillus, Thioalkalivibrio, Roseobacter). The abundances of sox genes were significantly higher in S2 than in S1 and S6 $(p<0.05)$, while no significant differences were found between $\mathrm{S} 2$ and $\mathrm{S} 3$. The $f c c A / B$ genes encoding flavocytochrome $c$ reductase for the initial step of sulfide oxidation were considered to be key genes for $S^{0}$ recovery (Friedrich, 1997). A total of $56 \mathrm{fccA} / \mathrm{B}$ genes were detected in 4 stage samples. Similar to sox genes, the highest abundance of $f c c A / B$ genes was observed in $\mathrm{S} 2$, which had significant difference with $\mathrm{S} 1$ and S6 ( $p<0.05)$, indicating that the microbial sulfide oxidation was stimulated at DO of $0.09 \mathrm{mg} / \mathrm{L}$ and inhibited when DO was $0.33 \mathrm{mg} / \mathrm{L}$. To further analyze $f c c A / B$ genes, hierarchical clustering analysis was performed. As shown in Fig. 5, $f c c A / B$ genes from colorless and green sulfur bacteria were more abundant in the bioreactor. Almost all $f c c A / B$ genes were detected in $\mathrm{S} 2$, while parts of them were not detected in S1 and S6. Moreover, the signal intensity for individual genes varied with different DO concentration conditions. Among these, sixteen $f c c A / B$ gene variants showed significant increasing trends at the $p<0.05$ level in $\mathrm{S} 2$ compared to $\mathrm{S} 1$, while thirty gene

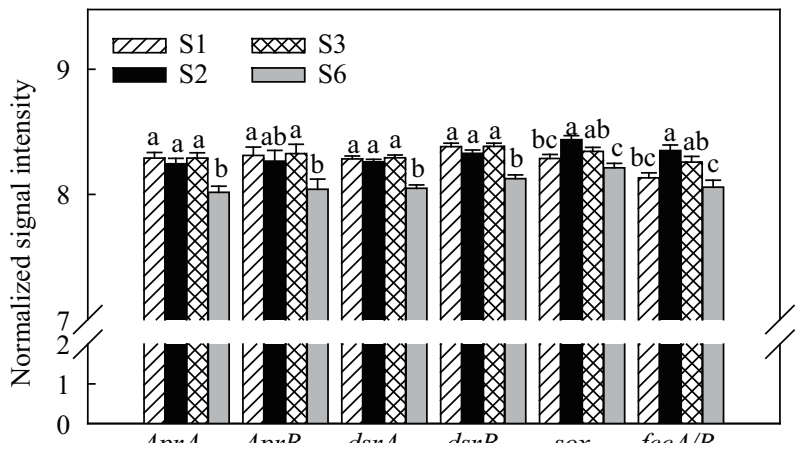

Fig. 4 Normalized average signal intensity of key genes involved in sulfur metabolism process. The signal intensity was the average abundances of gene sequences for each gene among 3 replicates. All data are presented with mean \pm SE. Letters represent significant differences among stages at $p<0.05$ by LSD test. variants showed significant decreasing trends at $p<0.05$ level in S6 compared to S2 (Fig. $\mathbf{S 2}$ and S3 in supplementary data). Notably, five $f c c A / B$ genes from popular colorless sulfur bacteria changed significantly in S1, S2 and S6, including Beggiatoa sp. SS (152145946), Paracoccus denitrificans PD1222 (119377458), Sulfuricurvum kujiense DSM 16994 (313682156), Thioalkalimicrobium cyclicum ALM1 (334143103), and Thiobacillus denitrificans ATCC 25259 (74318053). They were below detectable limits or had relatively low abundance in S1 and S6, but were present or well enriched in S2 (Fig. 6). Moreover, four $f c c A / B$ genes from green sulfur bacteria (Chlorobium limicola DSM 245 (189345569), Chlorobium phaeobacteroides DSM 266 (119353654), Chlorobium phaeovibrioides DSM 265 (145205130) and Chlorobium tepidum TLS (21674891)) significantly decreased in S6 compared to $\mathrm{S} 2(p<0.05)$ (Fig. S3).

\section{Discussion}

Limited oxygen supply to anaerobic reactors has been confirmed to have significant effects on the improvement of overall $\mathrm{S}^{0}$ conversion efficiencies of bioreactors (Lohwacharin and Annachhatre, 2010). However, the $S^{0}$ conversion efficiencies of bioreactors decreased with the continuous increase of DO levels (Xu et al., 2012). This might be due to the significant influence of DO on the microbial functional communities, but to date, the related mechanisms are still unclear. This study comprehensively characterized the diversity, structure and metabolic potential of microbial communities and investigated the shift of functional species in response to elevated DO levels.

GeoChip data analysis showed that DO significantly altered the overall diversity, structure and composition of microbial communities. Elevated DO levels may stimulate the growth of heterotrophic microorganisms, especially fermentative microorganisms, which were at low abundance in the initial stage. Although the activities of fermentative microorganisms were not evaluated, our results were consistent with previous studies of sulfate reducing reactors, which demonstrated that elevated DO level can increase lactate consumption by stimulating the growth of fermentative microorganisms (Celis-García et al., 2008). In addition, this inference was also supported by the analysis of the carbon degradation gene category, whose abundance increased with elevated DO level, as well as the change of COD removal efficiency (Fig. 3). However, the thriving of fermentative microorganisms was harmful to granular sludge (Baloch et al., 2008), and granule disintegration and flotation was observed in stage VI.

The SRB are generally found to be abundant in sulfateladen wastewater treatment processes (Dar et al., 2007; Kjeldsen et al., 2004; Wang et al., 2008). It has commonly 


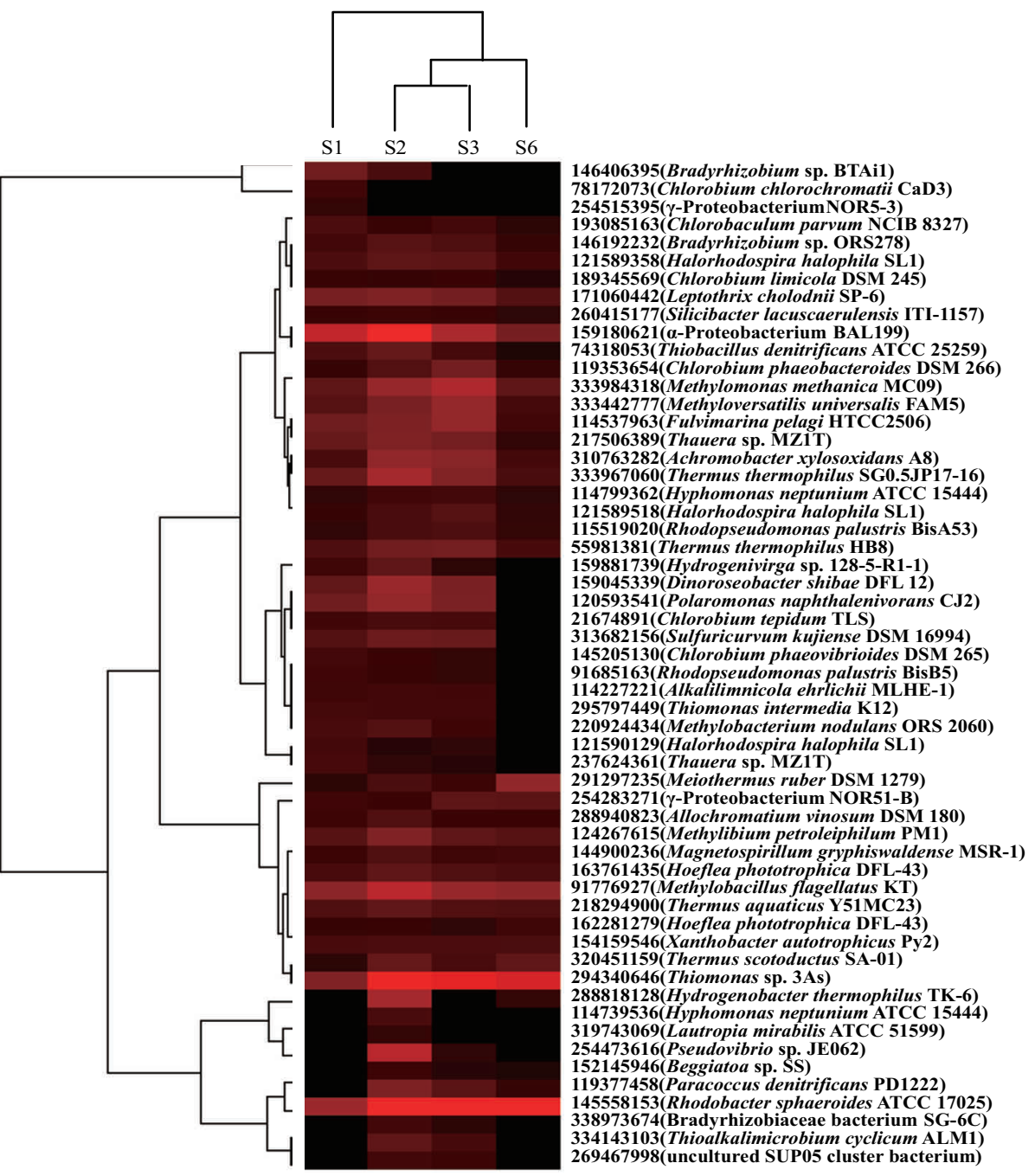

Fig. 5 Hierarchical cluster analysis of $f c c A / B$ genes for sulfide oxidation. S1, S2, S3, S6 represent the samples collected from stage I, II, III, VI. The abundance was the average signal intensity for each probe among 3 replicates. The figure was generated by CLUSTER and visualized using TREEVIEW. Red indicates signal intensities above threshold value, and black indicates signal intensities below threshold value, and brighter red color represents higher signal intensities.

been accepted that SRB are strict anaerobes. However, a growing number of studies have demonstrated that some SRB can tolerate a certain degree of DO (Abdollahi and Wimpenny, 1990; Cypionka et al., 1985; Fareleira et al., 2003; Mogensen et al., 2005). Consistently, no significant differences in the abundance of $d s r A / B$ genes were observed between $\mathrm{S} 1, \mathrm{~S} 2$ and $\mathrm{S} 3$, indicating that low levels of DO had less effect on SRB in the bioreactor. On the other hand, the capability of SRB for oxygen tolerance was species-dependent. A high level of DO was detrimental to both the growth rate and viability of SRB (Cypionka et al., 1985; Marschall et al., 1993; Mukhopadhyay et al., 2007). GeoChip data also showed the inhibition effect of high concentrations of DO $(0.33 \mathrm{mg} / \mathrm{L})$ on SRB, such that lower numbers and significantly lower abundances of $d s r A / B$ genes $(p<0.05)$ were detected in S6 than in S1, $\mathrm{S} 2$ and S3. In addition, the SRB may be supressed due to the thriving of fermentation microorganisms in stage
VI that can strongly compete for carbon resources with SRB (Celis-García et al., 2008). Although the chemical oxidation velocity of reduced sulfur compounds to sulfate was not evaluated, undoubtedly, the low abundance of SRB may be one of the major reasons for low sulfate removal efficiency in stage VI.

In contrast to $\mathrm{SRB}$, the $\mathrm{SOB}$ were more sensitive to oxygen. The abundances of sox and $f c c A / B$ genes significantly increased $(p<0.05)$ in $\mathrm{S} 2$ at $\mathrm{DO}=0.09 \mathrm{mg} / \mathrm{L}$ (Fig. 4), suggsting that the sulfide oxidation process may be stimulated at stage II. This inference was supported by the great increase of the $S^{0}$ conversion efficiency in stage II, while the sulfate removal efficiency slightly decreased. The change of sulfate removal efficiency may due to the fact that the thriving SOB oxidized part of the reduced sulfur compounds to sulfate. Interestingly, the abundance of carbon fixation genes, especially Rubisco genes, increased significantly $(p<0.05)$ in S2 compared 


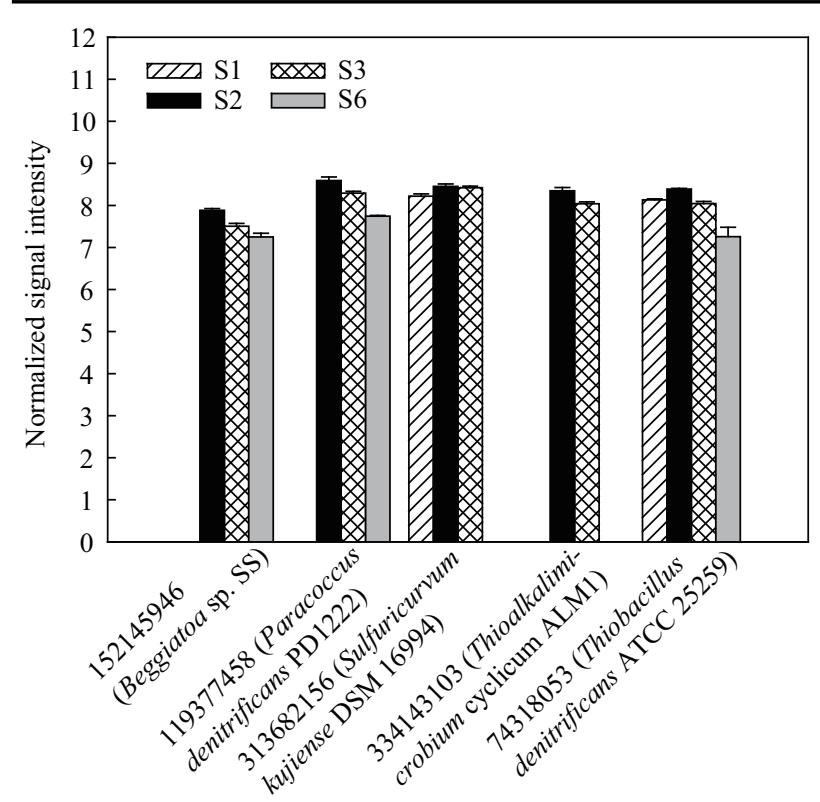

Fig. 6 Normalized signal intensity of $f c c A / B$ genes derived from some colorless sulfur bacteria, including Beggiatoa sp. SS, Paracoccus denitrificans PD1222, Sulfuricurvum kujiense DSM 16994, Thioalkalimicrobium cyclicum ALM1 and Thiobacillus denitrificans ATCC 25259. The number is GenBank accession number for each probe.

to S1 (Fig. S1 in supplementary data). The Calvin-BensonBassham cycle is the most common carbon fixation pathway for chemolithoautotrophic microorganisms. As one of the key enzymes for the Calvin cycle, Rubisco was particularly used for studying chemoautotrophic SOB in different habitats (Tourova, 2006; Tourova et al., 2010). The increased abundance of carbon fixation genes may be due to the thriving of chemoautotrophic SOB, although further phylogenetic studies are needed to support the hypothesis. Since the contribution of chemical sulfide oxidation to total sulfide oxidation rates was negligible at low DO level (Xu et al., 2012), biological oxidation was the major process responsible for $\mathrm{S}^{0}$ conversion. Additionally, the abundance of sox and $f c c A / B$ genes decreased with the continuous increase of DO levels (Fig. 4), and this trend was consistent with the decrease in $\mathrm{S}^{0}$ conversion efficiencies. This could be attributed to the fact that SOB were gradually inhibited by the thriving of heterotrophic microorganisms, which can effectively compete with SOB for available oxygen (van der Zee et al., 2007). This inhibition effect was substantiated by the increased accumulation of sulfide from stages II $(24.3 \mathrm{mg} / \mathrm{L})$ to $\mathrm{V}$ $(197.7 \mathrm{mg} / \mathrm{L})$ in the bioreactor (Table 1). In stage VI, the SOB were further inhibited due to the disintegration of granular sludge in the EGSB reactor. The breaking of granules might cause an enrichment of non-granular biomass in the upstream zone that could severely impact the utilization of available sulfide and DO by SOB (Baloch et al., 2008). In addition, several $f c c A / B$ genes from green sulfur bacteria were detected in the bio-desulfurization system (Fig. 5). This is not very surprising since green sulfur bacteria could well adapt to the low light and low oxygen conditions (Beatty et al., 2005; Eisen et al., 2002; Overmann et al., 1992). However, they were not detected or had low abundances in stage VI due to the severe inhibition effect of high concentration oxygen (Marschall et al., 2010). This could be another possible explanation for the low $S^{0}$ conversion efficiency achieved in stage VI.

The $f c c A / B$ genes had been widely found in colorless, green and purple sulfur bacteria that participate in the conversion of sulfide to $\mathrm{S}^{0}$ in vitro (De Smet et al., 2001; Visser et al., 1997). In this study, five $f_{c}$ $c A / B$ genes from colorless sulfur bacteria Beggiatoa sp. SS, Paracoccus denitrificans PD1222, Sulfuricurvum kujiense DSM 16994, Thioalkalimicrobium cyclicum ALM1 and Thiobacillus denitrificans ATCC 25259 significantly changed with elevated DO levels (Figs. S2 and S3 in supplementary data). In comparison with other SOB (e.g. green sulfur bacteria), their abundances were in correspondence with the change of $\mathrm{S}^{0}$ conversion efficiencies in the bioreactor (Figs. 5 and 6). As shown in previously studies, these species exhibited high activities in oxidizing sulfide to $S^{0}$ using oxygen as electron acceptor (Beller et al., 2006; Kodama, 2004; Mußmann et al., 2007; Schütz et al., 1998; Sorokin, 2002). It was postulated that these colorless sulfur bacteria might be responsible for $\mathrm{S}^{0}$ conversion, and thus played a key role in the sulfide oxidation process.

\section{Conclusions}

This study demonstrates the notable effect of DO on microbial community structure, which was crucial to the overall performance of the bioreactor. Our results imply that the SOB can be greatly stimulated by low DO levels (DO: 0.09 $\mathrm{mg} / \mathrm{L}$ ). However, under relatively high DO levels (DO: $0.33 \mathrm{mg} / \mathrm{L}$ ), the SRB and SOB were strongly inhibited, while the heterotrophic microorganisms, especially fermentative microorganisms, were well enriched, leading to granular disintegration. Thus, maintaining an optimum DO level was more important for the bio-desulfurization process, which in turn could improve the overall performance of the bioreactor. GeoChip-based analysis of functional microbial communities provides us with valuable information to improve reactor performance, and prevent or diagnose the common problems of bioreactors.

\section{Acknowledgments}

This work was supported by the National High-Tech Research and Development Program (863) of China (No. 2011AA060904), by the National Natural Science Foundation of China (No. 51111140388, 51176037 and 51308147), the National Creative Research Groups Project (No. 51121062), the State Key Laboratory of Urban Water Resource and Environment (No. 2012DX06), and the 
Liaoning Provincial Science and Technology Project (No. L2010169). We thank Dr. Jizhong Zhou and Zhili He from the University of Oklahoma for their help in providing hybridization system and GeoChip data statistical analysis.

\section{Supporting materials}

Supplementary data associated with this article can be found in the online version.

\section{R E F E R E N C E S}

Abdollahi, H., Wimpenny, J.W.T., 1990. Effects of oxygen on the growth of Desulfovibrio desulfuricans. J. Gen. Microbiol. 136(6), 10251030.

Bai, S., Li, J., He, Z., Nostrand, J., Tian, Y., Lin, G. et al., 2013. GeoChipbased analysis of the functional gene diversity and metabolic potential of soil microbial communities of mangroves. Appl. Microbiol. Biotechnol. 97(15), 7035-7048.

Baloch, M.I., Akunna, J.C., Kierans, M., Collier, P.J., 2008. Structural analysis of anaerobic granules in a phase separated reactor by electron microscopy. Bioresour. Technol. 99(5), 922-929.

Beatty, J.T., Overmann, J., Lince, M.T., Manske, A.K., Lang, A.S., Blankenship, R.E. et al., 2005. An obligately photosynthetic bacterial anaerobe from a deep-sea hydrothermal vent. Proc. Natl. Acad. Sci. USA 102(26), 9306-9310.

Beller, H.R., Chain, P.S.G., Letain, T.E., Chakicherla, A., Larimer, F.W., Richardson, P.M. et al., 2006. The genome sequence of the obligately chemolithoautotrophic, facultatively anaerobic bacterium Thiobacillus denitrificans. J. Bacteriol. 188(4), 1473-1488.

Celis-García, L.B., González-Blanco, G., Meraz, M., 2008. Removal of sulfur inorganic compounds by a biofilm of sulfate reducing and sulfide oxidizing bacteria in a down-flow fluidized bed reactor. J. Chem. Technol. Biotechnol. 83(3), 260-268.

Chen, C., Ren, N., Wang, A., Yu, Z., Lee, D.J., 2008. Simultaneous biological removal of sulfur, nitrogen and carbon using EGSB reactor. Appl. Microbiol. Biotechnol. 78(6), 1057-1063.

Cypionka, H., Widdel, F., Pfennig, N., 1985. Survival of sulfate-reducing bacteria after oxygen stress, and growth in sulfate-free oxygensulfide gradients. FEMS Microbiol. Lett. 31(1), 39-45.

Dambe, T., Quentmeier, A., Rother, D., Friedrich, C., Scheidig, A.J., 2005. Structure of the cytochrome complex SoxXA of Paracoccus pantotrophus, a heme enzyme initiating chemotrophic sulfur oxidation. J. Struct. Biol. 152(3), 229-234.

Dar, S.A., Yao, L., van Dongen, U., Kuenen, J.G., Muyzer, G., 2007. Analysis of diversity and activity of sulfate-reducing bacterial communities in sulfidogenic bioreactors using 16S rRNA and $d s r B$ genes as molecular markers. Appl. Environ. Microbiol. 73(2), 594604.

de Graaff, M., Klok, J.B.M., Bijmans, M.F.M., Muyzer, G., Janssen, A.J.H., 2012. Application of a 2-step process for the biological treatment of sulfidic spent caustics. Water Res. 46(3), 723-730.

De Smet, L., Kostanjevecki, V., Guisez, Y., Van Beeumen, J., 2001. A novel system for heterologous expression of flavocytochrome $\mathrm{c}$ in phototrophic bacteria using the Allochromatium vinosum rbcA promoter. Arch. Microbiol. 176(1-2), 19-28.

Eisen, J.A., Nelson, K.E., Paulsen, I.T., Heidelberg, J.F., Wu, M., Dodson, R.J. et al., 2002. The complete genome sequence of Chlorobium tepidum TLS, a photosynthetic, anaerobic, green-sulfur bacterium. Proc. Natl. Acad. Sci. USA 99(14), 9509-9514.

Fareleira, P., Santos, B.S., António, C., Moradas-Ferreira, P., LeGall, J., Xavier, A.V. et al., 2003. Response of a strict anaerobe to oxygen: survival strategies in Desulfovibrio gigas. Microbiology 149(6), 1513-1522.

Friedrich, C.G., 1997. Physiology and Genetics of Sulfur-oxidizing Bacteria. In: Poole, R.K. (Ed.). Advances in Microbial Physiology, Vol. Volume 39. Academic Press, pp. 235-289.

Friedrich, C.G., Bardischewsky, F., Rother, D., Quentmeier, A., Fischer, J., 2005. Prokaryotic sulfur oxidation. Curr. Opin. Microbiol. 8(3), 253-259.

Friedrich, C.G., Quentmeier, A., Bardischewsky, F., Rother, D., Kraft, R., Kostka, S. et al., 2000. Novel genes coding for lithotrophic sulfur oxidation of Paracoccus pantotrophus GB17. J. Bacteriol. 182(17), 4677-4687.

He, Z., Deng, Y., Van Nostrand, J.D., Tu, Q., Xu, M., Hemme, C.L. et al., 2010. GeoChip 3.0 as a high-throughput tool for analyzing microbial community composition, structure and functional activity. ISME J. 4(9), 1167-1179.

Huang, C., Chung, Y.C., Hsu, B.M., 1996. Hydrogen sulfide removal by immobilized autotrophic and heterotrophic bacteria in the bioreactors. Biotechnol. Techni. 10(8), 595-600.

Janssen, A.J.H., Sleyster, R., van der Kaa, C., Jochemsen, A., Bontsema, J., Lettinga, G., 1995. Biological sulphide oxidation in a fed-batch reactor. Biotechnol. Bioeng. 47(3), 327-333.

Jost, G., Martens-Habbena, W., Pollehne, F., Schnetger, B., Labrenz, M., 2010. Anaerobic sulfur oxidation in the absence of nitrate dominates microbial chemoautotrophy beneath the pelagic chemocline of the eastern Gotland Basin, Baltic Sea. FEMS Microbiol. Ecol. 71(2), 226-236.

Kjeldsen, K.U., Joulian, C., Ingvorsen, K., 2004. Oxygen tolerance of sulfate-reducing bacteria in activated sludge. Environ. Sci. Technol. 38(7), 2038-2043.

Kobayashi, T., Li, Y.Y., Kubota, K., Harada, H., Maeda, T., Yu, H.Q., 2011. Characterization of sulfide-oxidizing microbial mats developed inside a full-scale anaerobic digester employing biological desulfurization. Appl. Microbiol. Biotechnol. 93(2), 847-857.

Kodama, Y., 2004. Sulfuricurvum kujiense gen. nov., sp. nov., a facultatively anaerobic, chemolithoautotrophic, sulfur-oxidizing bacterium isolated from an underground crude-oil storage cavity. Inter. J. Syst. Evolut. Microbiol. 54(6), 2297-2300.

Liu, W.Z., Wang, A.J., Cheng, S.A., Logan, B.E., Yu, H., Deng, Y. et al., 2010. Geochip-based functional gene analysis of anodophilic communities in microbial electrolysis cells under different operational modes. Environ. Sci. Technol. 44(19), 7729-7735.

Lohwacharin, J., Annachhatre, A.P., 2010. Biological sulfide oxidation in an airlift bioreactor. Bioresour. Technol. 101(7), 2114-2120.

Luo, J.F., Lin, W.T., Guo, Y., 2011. Functional genes based analysis of sulfur-oxidizing bacteria community in sulfide removing bioreactor. Appl. Microbiol. Biotechnol. 90(2), 769-778.

Marschall, C., Frenzel, P., Cypionka, H., 1993. Influence of oxygen on sulfate reduction and growth of sulfate-reducing bacteria. Arch. Microbiol. 159(2), 168-173.

Marschall, E., Jogler, M., Henßge, U., Overmann, J., 2010. Large-scale distribution and activity patterns of an extremely low-light-adapted population of green sulfur bacteria in the Black Sea. Environ. Microbiol. 12(5), 1348-1362. 
McComas, C., Sublette, K.L., Jenneman, G., Bala, G., 2001. Characterization of a novel biocatalyst dystem for sulfide oxidation. Biotechnol. Prog. 17(3), 439-446.

Mogensen, G.L., Kjeldsen, K.U., Ingvorsen, K., 2005. Desulfovibrio aerotolerans sp. nov., an oxygen tolerant sulphate-reducing bacterium isolated from activated sludge. Anaerobe 11(6), 339-349.

Mußmann, M., Hu, F.Z., Richter, M., de Beer, D., Preisler, A., Jørgensen, B.B. et al., 2007. Insights into the genome of large sulfur bacteria revealed by analysis of single filaments. PLoS Biol. 5(9), e230.

Mukhopadhyay, A., Redding, A.M., Joachimiak, M.P., Arkin, A.P., Borglin, S.E., Dehal, P.S. et al., 2007. Cell-wide responses to low-oxygen exposure in Desulfovibrio vulgaris Hildenborough. J. Bacteriol. 189(16), 5996-6010.

Overmann, J., Cypionka, H., Pfennig, N., 1992. An extremely low-lightadapted phototrophic sulfur bacterium from the black sea. Limnol. Oceanogr. 37(1), 150-155.

Rother, D., Henrich, H.J., Quentmeier, A., Bardischewsky, F., Friedrich, C.G., 2001. Novel genes of the sox gene cluster, mutagenesis of the flavoprotein SoxF, and evidence for a general sulfur-oxidizing system in Paracoccus pantotrophus GB17. J. Bacteriol. 183(15), 4499-4508.

Sahinkaya, E., Hasar, H., Kaksonen, A.H., Rittmann, B.E., 2011. Performance of a sulfide-oxidizing, sulfur-producing membrane biofilm reactor treating sulfide-containing bioreactor effluent. Environ. Sci. Technol. 45(9), 4080-4087.

Schütz, M., Klughammer, C., Griesbeck, C., Quentmeier, A., Friedrich, C.G., Hauska, G., 1998. Sulfide-quinone reductase activity in membranes of the chemotrophic bacterium Paracoccus denitrificans GB17. Arch. Microbiol. 170(5), 353-360.

Sorokin, D.Y., 2002. Thioalkalimicrobium cyclicum sp. nov. and Thioalkalivibrio jannaschii sp. nov., novel species of haloalkaliphilic, obligately chemolithoautotrophic sulfur-oxidizing bacteria from hypersaline alkaline Mono Lake (California). Inter. J. Syst. Evolut. Microbiol. 52(3), 913-920.

Sorokin, D.Y., Bosch, P.L.F., Abbas, B., Janssen, A.J.H., Muyzer, G., 2008. Microbiological analysis of the population of extremely haloalkaliphilic sulfur-oxidizing bacteria dominating in lab-scale sulfide-removing bioreactors. Appl. Microbiol. Biotechnol. 80(6), 965-975.

Tourova, T.P., 2006. Occurrence, phylogeny and evolution of ribulose1,5-bisphosphate carboxylase/oxygenase genes in obligately chemolithoautotrophic sulfur-oxidizing bacteria of the genera Thiomicrospira and Thioalkalimicrobium. Microbiology 152(7), 2159-2169.

Tourova, T.P., Kovaleva, O.L., Sorokin, D.Y., Muyzer, G., 2010. Ribulose1, 5-bisphosphate carboxylase/oxygenase genes as a functional marker for chemolithoautotrophic halophilic sulfur-oxidizing bacteria in hypersaline habitats. Microbiology 156(7), 2016-2025.

Trüper, H.G., Schlegel, H.G., 1964. Sulphur metabolism in Thiorhodaceae I. Quantitative measurements on growing cells of Chromatium okenii. Antonie van Leeuwenhoek 30(1), 225-238.

van der Zee, F.P., Villaverde, S., García, P.A., Fdz-Polanco, F., 2007. Sulfide removal by moderate oxygenation of anaerobic sludge environments. Bioresour. Technol. 98(3), 518-524.

Visser, J.M., de Jong, G.A.H., Robertson, L.A., Kuenen, J.G., 1997. A novel membrane-bound flavocytochrome c sulfide dehydrogenase from the colourless sulfur bacterium Thiobacillus sp. W5. Arch. Microbiol. 167(5), 295-301.

Wang, A., Ren, N., Wang, X., Lee, D., 2008. Enhanced sulfate reduction with acidogenic sulfate-reducing bacteria. J. Hazard. Mater. 154(13), 1060-1065.

Wu, L.Y., Liu, X.D., Schadt, C.W., Zhou, J.Z., 2006. Microarray-based analysis of subnanogram quantities of microbial community DNAs by using whole-community genome amplification. Appl. Environ. Microbiol. 72(7), 4931-4941.

Xu, X.J., Chen, C., Wang, A.J., Fang, N., Yuan, Y., Ren, N. et al., 2012. Enhanced elementary sulfur recovery in integrated sulfatereducing, sulfur-producing rector under micro-aerobic condition. Bioresour. Technol. 116, 517-521.

Zhou, J., Bruns, M.A., Tiedje, J.M., 1996. DNA recovery from soils of diverse composition. Appl. Environ. Microbiol. 62(2), 316-322.

Zhou, J., He, Z., Nostrand, J.D.V., Wu, L., Deng, Y., 2010. Applying geoChip analysis to disparate microbial communities. Microbe 5, $60-65$. 